\title{
Iniciação científica - contexto e aspectos práticos
}

\section{Undergraduate research mentorship - context and practicalities}

\author{
Luiz Fernando Ferraz da Silva
}

INTRODUÇÃO

$\mathrm{O}$ médico, desde a graduação, está envolto a uma grande quantidade de informações, não apenas nas aulas, mas através dos mais diferentes meios incluindo bibliotecas físicas e virtuais e conteúdos eletrônicos de diversas fontes. Muitas vezes o que se lhes disponibiliza é apresentado como tendo base científica, mas sabidamente isto não necessariamente ocorre. Surge então um fenômeno cada vez mais comum desde o fim dos anos 80 , onde a quantidade de informação deixa de ser um fator limitante e passa a ser até excessiva, desviando o foco para a qualidade das informações disponíveis. Neste contexto torna-se imperativo que o médico conheça o método científico e saiba utilizar estes conceitos como ferramenta na análise das informações disponíveis incluindo trabalhos publicados, livros, materiais impressos e apresentados em diferentes esferas.

Embora a necessidade e relevância deste processo tenha se evidenciado nas três últimas décadas, o envolvimento de alunos de graduação em pesquisa já é mais antigo no país e no mundo. Os Estados Unidos e a França foram pioneiros na institucionalização de programas de treinamento científico durante a graduação em medicina e estudo recentes já quantificaram diferentes impactos positivos como satisfação com a experiência de fazer ciência, perspectiva de maior dedicação à pesquisa, aumento da motivação para as atividades gerais do curso de graduação e interesse pela carreira acadêmica.
Assim surgiu a iniciação científica, que atualmente pode ser definida como a vivência prática do processo de fazer pesquisa sob orientação de um pesquisador qualificado tendo como objetivo conhecer os princípios do método científico e despertar a vocação científica incentivando talentos potenciais entre estudantes de graduação universitária.

No Brasil, os primeiros relatos de participação de alunos de graduação em projetos de pesquisa datam da década de 1940 através dos chamados alunos ajudantes. Porém, por cerca de 10 anos o processo ocorreu de forma não institucionalizada o que sempre dificultou o aumento da escala de participação. Em 1951 foi criado o Conselho Nacional de Pesquisa e Desenvolvimento (CNPq) o que abriu a oportunidade de apoio financeiro a pesquisadores através de bolsa, incluindo alunos de graduação. Porém, o número era restrito e a obtenção do auxílio dependia muito do orientador sendo as bolsas distribuídas de forma pouco ordenada. Porém, em 1988 o processo deu uma grande guinada com a criação do Programa Institucional de Bolsas de Iniciação Científica (PIBIC) pelo CNPq, que passa a conceder bolsas para alunos de graduação desenvolvendo atividades de pesquisa. $O$ sucesso do programa foi imediato e replicado pelas agências estaduais de fomento, como a FAPESP (Fundação de Amparo à Pesquisa do Estado de São Paulo), FAPERJ (Fundação de Amparo à Pesquisa do Estado

Professor do Departamento de Patologia, Faculdade de Medicina da Universidade de São Paulo - FMUSP.

Endereço para correspondência: Luiz Fernando Ferraz da Silva. Av. Dr. Arnaldo, 455 - 1 Andar - Sala 1155 - São Paulo, SP, CEP: 01246-903. e-mail: burns@usp.br 
Silva LFF. Iniciação científica: contexto e aspectos práticos.

do Rio de Janeiro), FAPEMIG (Fundação de Amparo à Pesquisa do Estado de Minas Gerais), entre outras. Apenas para se ter idéia da dimensão alcançada pela iniciação científica no país, o estudo mais recente disponível sobre o tema mostra que o programa está presente em $80 \%$ das instituições públicas de ensino superior e em $71 \%$ das instituições privadas de ensino superior, embora a institucionalização com definição específica de carga horária, grade de orientadores e estratégias de divulgação ainda não estejam bem estabelecidas em todas elas.

Estudos sobre o impacto da iniciação científica no Brasil são escassos, mas os atualmente disponíveis mostraram que, em geral, todos os estudantes que fizeram iniciação científica têm melhor desempenho nas seleções para a pós-graduação, terminam mais rápido a titulação, possuem um treinamento mais coletivo e com espírito de equipe e detêm maior facilidade de falar em público e de se adaptar às atividades didáticas futuras.

Do ponto de vista de interpretação do aluno um estudo nacional mostrou que dentre os cerca de $78 \%$ dos alunos que fizeram iniciação científica apenas $25 \%$ consideraram que ela teve participação ampla em sua formação - diferente do observado em experiências internacionais onde esses níveis chegam a $80 \%$, e $20 \%$ disseram que a iniciação científica teve pouca ou nenhuma participação em sua formação.

Ao se comparar estes dados com os internacionais citados percebemos que algumas dificuldades podem influir nesta percepção. As duas maiores delas segundo estudos são a escassez de verbas - que limita o número de bolsas e financiamento de projetos - e a falta de institucionalização, que acaba sendo crítica especialmente nos cursos realizados em tempo integral como a medicina. Diferente de cursos em tempo parcial onde normalmente o aluno tem meio período diário para execução de atividades extra-curriculares opcionais, o aluno de medicina não tem esta possibilidade, restando-lhes os períodos noturnos e intervalos entre aulas. Neste sentido a institucionalização pode contribuir abrindo espaços específicos para a realização destas atividades. Embora isto seja claro, ainda não é aplicado pela maioria das escolas médicas no país.

Atualmente na Faculdade de Medicina da Universidade de São Paulo (FMUSP) estes são dois impedimentos que se não foram completamente superados, foram bastante minimizados. A Faculdade conta hoje com número considerável de bolsas do programa PIBIC além de um número considerável de bolsas de Iniciação Científica da FAPESP, de forma que, segundo os dados disponíveis, poucos são os alunos que num intervalo de dois anos de atividade não conseguem aplicar ou solicitar uma bolsa (sem excluir aqueles que não podem requerer por impedimentos regimentais dos programas). Do ponto de vista da institucionalização, a FMUSP também deu largos passos com o estabelecimento das disciplinas optativas de "Introdução à Pesquisa Científica em Medicina" e disciplinas correlatas que permitem aos alunos utilizar as áreas verdes do currículo e desenvolver atividades de pesquisa como disciplinas optativas. A Faculdade e o Hospital das Clínicas contam ainda com 62 laboratórios de investigação médica e outros laboratórios vinculados que recebem alunos de iniciação científica orientados por docentes e pesquisadores do complexo. Com toda esta estrutura a FMUSP vem cada vez mais, valorizando as atividades de iniciação científica na formação de seus alunos.

\section{Perguntas frequentes sobre iniciação científica}

Considerando todo este leque de possibilidades e alternativas, é natural que os alunos, em especial os mais jovens, tenham uma série de dúvidas a respeito a iniciação científica em termos de por que fazer, o que esperar, direitos e deveres, que laboratório escolher, relevância para a formação, importância curricular entre outros. Neste sentido, selecionamos algumas das perguntas mais freqüentes sobre iniciação científica que não tem a pretensão de dirimir todas as dúvidas e angústias relacionadas ao processo, mas que pode ser um bom ponto de partida para aqueles que estão com intenção de "se aventurar em busca do desconhecido na ciência". Então vamos a elas:

\section{Qual a função da iniciação científica?}

A função básica da iniciação científica é colocar o aluno de graduação em contato com o método científico, isto é, com as diferentes etapas do processo de pesquisa, desde a primeira idéia para um trabalho até os detalhes finais de divulgação dos resultados obtidos. Além disso, uma vez que o aluno tenha estas noções básicas do método científico, ele torna-se mais crítico ao fazer a leitura de um artigo científico, sabendo apontar os pontos fortes e pontos fracos dos trabalhos publicados, o que agrega um conhecimento muito importante, que é a seleção do que se vai ler ou estudar.

Além disso, o desbravamento de um tema e seu estudo mais detalhado fornece ao aluno em formação um excelente exemplo de descoberta e busca, fazendo com que ele passe a perder o medo do desconhecido, virtude que será extremamente importante em momentos posteriores da formação 
e do exercício profissional.

Um objetivo adicional é possibilitar ao aluno o conhecimento de uma nova vertente de atuação, a de pesquisador, que poderá ser ou não adotada por ele posteriormente em outras fases de vida.

\section{Como é feito um projeto de iniciação científica?}

Um projeto de iniciação científica pode ter particularidades, mas, via de regra, segue um modelo geral único com passos semelhantes independente do tema e da área de estudo. Para exemplificar o passo a passo de um projeto científico, vamos utilizar um exemplo e a partir daí pensar no desenvolvimento passo a passo do projeto. Imagine que você fará iniciação científica junto ao grupo de pesquisa em patologia de autópsias da faculdade.

a) Seleção das oportunidades de pesquisa: normalmente esta etapa é feita em conjunto com o orientador. Uma idéia original pode sair de qualquer ponto, mas é especialmente natural quando alguém já conhece bem a fundo determinado tema, isto porque geralmente esta pessoa acompanha as pesquisas relacionadas e conhece o que vem sendo produzido em determinada área bem como os chamados "vazios de conhecimento", isto é, perguntas que ainda não estão respondidas sobre o tema, e que podem ser bom alvo de pesquisa. Portanto, converse com o seu orientador, ele poderá dar boas dicas de oportunidades de pesquisa na área dele.

Exemplificando: No nosso exemplo, utilizar o material de autópsia como ferramenta de pesquisa é bastante interessante, pois o número de autópsias vem caindo em todo o mundo e o Hospital das Clínicas e o Serviço de Verificação de Óbitos da Capital (sediado no prédio da FMUSP) formam em conjunto o maior centro mundial de realização de autópsias em indivíduos falecidos por causas naturais. Porém, isto ainda é muito genérico. Podemos então ser mais específicos e definir estudar a correlação entre exames de imagem realizados em cadáveres e comparar estes achados com os resultados da autópsia convencional. Mas ainda assim temos um projeto muito grande e genérico. Um desafio cientificamente relevante e mais factível é, por exemplo, avaliar a correlação entre a tomografia post-mortem de fígado em pacientes falecidos com doenças hepáticas e os achados da autópsia, para avaliar em quantos casos os achados de autópsia poderiam ser identificados apenas com a tomografia ou com a tomografia guiando uma biópsia por agulha evitando assim um procedimento mais invasivo.

b) Levantamento bibliográfico: com uma idéia em mente é fundamental que o graduando conheça mais a fundo o tema e detalhes dele. Pode-se começar a estudá-lo em um bom livro, que geralmente traz todo o conhecimento consolidado sobre determinado tema. Porém, quando pensamos na velocidade de desenvolvimento da ciência e no número de informações novas produzidas a cada dia, fica claro que o conhecimento presente nos livros em geral está desatualizado já na data da publicação. Nesta fase entram os artigos científicos, publicados em revistas ou periódicos médicos. A plataforma mais utilizada para buscar artigos e identificar aqueles potencialmente interessantes é o PubMed (www.pubmed.gov) que está ligado à base de dados Medline, a maior base de informações científicas da área médica do planeta. Neste portal é possível ter acesso a um sem número de publicações e artigos. A busca é bastante simples, realizada através de palavras chave. Ao buscar por uma ou mais palavras chave um grande número de artigos será apresentado e aí vem o grande desafio: destes artigos todos quais devo ler?

Este é um dos grandes desafios atuais: frente à grande quantidade de informação, torna-se fundamental selecionar as mais importantes e ter uma visão crítica. Geralmente o título pode ser indicativo de que um determinado artigo serve (ou não) para o seu propósito de estudo. A seguir é importante ler com mais atenção o resumo do artigo e por fim o artigo por inteiro para se identificar se ele é metodologicamente correto, se tem informações relevantes para aquilo que você pretende estudar, entre outros. Uma dica importante - ler o tópico "método" de um artigo pode parecer enfadonho no início, mas você perceberá que ele tem duas grandes funções para você: 1) descobrir que uma mesma coisa pode ser investigada usando métodos diferentes, e 2) saber reconhecer se aquele projeto foi executado corretamente.

Voltando ao nosso exemplo, no levantamento bibliográfico seria interessante ter artigos que falassem de tomografia de fígado, correlação de achados de tomografia com biópsias de fígado em indivíduos vivos, uso de tomografias em autópsias, achados de doenças hepáticas em autópsias. Note que nenhum artigo abrangerá todos os aspectos do que você irá pesquisar (se isso acontecer, cuidado, seu trabalho pode não ser tão original assim!). Desta forma, busque ter um número considerável de artigos que sejam complementares e que lhe dê boa base sobre o tema que será estudado.

Dica: as unidades da USP em conjunto assinam a maior parte das revistas da área de saúde. Ao estar num computador da rede da universidade o acesso é gratuito e imediato às versões eletrônicas dos artigos. A USP disponibiliza ainda gratuitamente a todos os alunos e professores uma conexão VPN (do inglês 
Virtual Private Network) que de forma simplista, faz com que o seu computador doméstico ou laptop seja reconhecido como parte da rede da USP permitindo que você acesse de casa todos os artigos como se estivesse na biblioteca da faculdade. Para maiores informações acesse o site www.vpn.usp.br/.

c) Escrever o projeto: O Projeto é o seu plano de pesquisa. Ele é um documento estruturado que traz, da forma mais detalhada possível, informações sobre o planejamento de sua pesquisa. Ele deve conter:

1. Introdução: Feita com base no seu levantamento bibliográfico, deve fornecer ao leitor de forma clara e objetiva as informações básicas sobre o tema que você irá pesquisar. No nosso exemplo, é importante falar sobre a tomografia computadorizada e sua importância como ferramenta diagnóstica na medicina atual, sobre a autópsia e sua relevância para identificação das causas de óbito e no controle de qualidade, sobre as principais doenças hepáticas e sua relevância em termos de saúde pública;

2. Objetivo: O objetivo pode ser traçado em itens primários e secundários, ou mais comumente como uma pergunta de pesquisa ou hipótese diagnóstica. O objetivo deve ser curto e muito claro, restringindo-se ao que você irá pesquisar. Não tente abraçar o mundo!;

3. Método: Nesta seção deve se detalhada toda a metodologia a ser utilizada no seu trabalho, do número de pacientes ou animais até a análise estatística. O principal objetivo desta seção é que qualquer outro pesquisador que queira reproduzir o seu trabalho consiga fazer exatamente da mesma forma para comparar os dados ou aplicar esta estratégia em estudos com outros objetivos, portanto, seja bastante detalhista e claro. Todos os processos devem ser descritos, de preferência apresentando as referências bibliográficas quando forem utilizados processos já descritos e consagrados na literatura. No nosso exemplo, precisaremos colocar o número de pacientes, critérios de inclusão (ter doença hepática) e exclusão (pacientes transplantados) do estudo, método de realização da tomografia (incluindo a marca e tipo do tomógrafo e características da aquisição de imagem), método de realização da autópsia, análise dos dados e testes estatísticos a serem utilizados para avaliação da correlação entre os dados de tomografia e autópsia;

4. Cronograma: Um cronograma é fundamental para descrever as diferentes etapas, seu fluxo de trabalho e em quanto tempo espera-se atingir os objetivos propostos. Isto é fundamental para a avaliação pelas diversas instituições pelas quais os projetos passam, incluindo as comissões científicas dos departamentos, comissão de ética e agências de fomento. O cronograma deverá conter os passos mais importantes de seu projeto.

Dica: Ao tentar escrever seu primeiro projeto, não se assuste! Isto é sempre desafiador. É uma grande quantidade de informação nova e ainda não se domina muito bem toda a metodologia, de forma que a ajuda do seu orientador será fundamental para isso. Você verá que, quando tiver que repetir estas etapas no seu relatório ou mesmo escrever um novo projeto, você terá mais prática. Como tudo na vida isto é um processo contínuo de aprendizado. Lembre-se, todo grande pesquisador um dia teve dificuldades para escrever seu primeiro projeto!

d) Execução do trabalho: Esta será a fase que the tomará realmente bastante tempo. Nela todo o projeto será executado, isto é, tudo o que foi descrito na metodologia será posto em prática. Aqui cada atividade depende obviamente do tipo de projeto. Você certamente aprenderá muito sobre técnicas específicas utilizadas no seu trabalho. Isto será muito importante, mas lembre-se, sua função não é apenas dominar uma técnica ou procedimento, é conhecer o método científico, portanto, não se restrinja à aplicação da técnica - escrever o projeto e discutir os resultados é fundamental.

No nosso exemplo teremos que selecionar os pacientes que chegarem ao serviço de autópsias com suspeita de doenças hepáticas, realizar e analisar a tomografia abdominal e ver se há alterações no fígado. Realizar a autópsia e examinar macroscopicamente e microscopicamente o fígado, sistematizar os dados que serão obtidos e tabulados de cada caso e depois fazer a análise estatística destes dados vendo quais informações têm correlação ou não.

Análise dos dados: Uma vez aplicada a metodologia e obtidos os dados é preciso analisálos criticamente, isto é, compreender o que eles significam no contexto da doença ou do processo estudado. O resultado não é apenas uma sopa de números e tabelas, mas sim uma apresentação sistematizada e ordenada de informações que permitem a compreensão das novas informações geradas como parte de um contexto maior. Nesta fase, novamente seu orientador será fundamental para tirar dúvidas e esclarecer quais informações são realmente relevantes e quais são as secundárias.

e) Divulgação dos resultados: Com todas as informações em mãos, chega a última parte do projeto, a divulgação dos resultados, ela pode ser feita de diferentes formas (não mutuamente 
excludentes, ao contrário) a saber:

a. Artigo científico: é a mais importante forma de divulgação da ciência. A partir deste momento o resultado da sua pesquisa contribuirá para incrementar o conhecimento científico como mais um tijolo no muro. $\mathrm{O}$ artigo tem um formato específico como você deve ter observado no levantamento bibliográfico: Introdução, objetivo, método, resultados e discussão;

b. Relatórios: Geralmente necessários para agências de fomento que pagam bolsas. Ele segue o mesmo formato do artigo, mas geralmente não tem limitação de espaço e você pode ser bem detalhado. Não seja simplista, venda o seu peixe!;

c. Apresentação em eventos: geralmente uma versão mais curta do trabalho, apresentado de forma objetiva e concisa em uma apresentação oral curta (até 10 minutos) ou painel (5 minutos). 0 grande atrativo deste formato é a possibilidade de discussão em tempo real com outros pesquisadores da mesma área, o que favorece a troca de idéias e o crescimento científico de todos os envolvidos. Às vezes, um comentário ou observação de alguém que enxerga seu trabalho "de fora" é fundamental para lhe dar uma idéia nova ou então apontar um ponto fraco do seu trabalho que você não havia percebido.

\section{O que esperar da iniciação científica?}

Ao decidir fazer iniciação científica tenha claro que você desenvolverá um projeto voltado para o reconhecimento e aplicação do método científico. Pode ser que no seu projeto, o atendimento a pacientes seja uma parte do método - especialmente em trabalho clínicos com informações prospectivas, mas, diferente da graduação, o atendimento ao paciente não deve ser o fim, mas sim o meio. Se você está se propondo a fazer iniciação científica para ter contato com pacientes, existem muitas outras atividades que podem ser desenvolvidas de forma mais eficiente com este fim como ligas acadêmicas e projetos de extensão. Obviamente, muitas ligas e projetos de extensão têm iniciação científica com uma de suas possibilidades, mas neste caso, buscando a aplicação do método científico como parte de suas atividades, adicionalmente à sua atividade assistencial.

Ao decidir fazer iniciação científica espere estudar bastante determinado tema (qualquer que seja ele), aprender uma ou mais técnicas que serão usadas na sua metodologia (técnica aqui inclui tudo - análise de prontuário, atividade de laboratório, análise de imagem em computador - e depende das características do seu projeto), e aprender a ler criticamente um artigo científico sabendo interpretá-lo e identificar pontos fortes e fracos contextualizando estas informações dentro da base de conhecimentos que você possui.

\section{Que tipos de projeto de iniciação científica existem?}

Os estudos científicos podem ser divididos de acordo com diferentes critérios. Os mais comuns estão relacionados aos diferentes modelos de estudo e que não vou entrar em detalhes neste artigo uma vez que farão parte de toda uma disciplina nuclear do curso médico. Vou apresentar aqui uma visão mais simplista que pode ser descrita como "a divisão dos estudos do ponto de vista do aluno que procura iniciação científica".

\section{Dos sujeitos dos trabalhos}

a) Trabalhos experimentais: são os projetos que tem uma grande quantidade de trabalho de bancada. São trabalhos desenvolvidos em animais de experimentação (camundongos, ratos, coelhos, porcos, etc.). Geralmente incluem a realização de algum experimento com o animal (treinamento, exposição a um produto ou substância, procedimento cirúrgico, etc.), o sacrifício deste animal, e a análise de dados, órgãos, fluidos e tecidos.

b) Trabalhos com humanos: são todos aqueles que envolvem, de alguma forma seres humanos, direta ou indiretamente através de informações e/ou materiais oriundos destes indivíduos e armazenados no hospital.

\section{Das atividades desenvolvidas}

a) Procedimentos: Procedimentos nos projetos de iniciação científica podem ser diversos. Os mais invasivos geralmente são realizados em animais (como cirurgias ou coleta direta de materiais) enquanto outros podem ser desenvolvidos em humanos como exames de imagem, provas de função pulmonar, eletrocardiogramas e eletroencefalogramas, etc.

b) Trabalho de bancada: O trabalho de bancada laboratorial pode ser extremamente interessante, especialmente por ser uma atividade que você não terá oportunidade de aprender no curso de medicina. Ele inclui atividades práticas do tipo extração de material genético e outras técnicas de biologia molecular, técnicas de exames bioquímicos, preparo de soluções, culturas de células entre muitos outros. Estes são apenas alguns exemplos. Para quem tem curiosidade de conhecer uma técnica laboratorial e como ela é realizada, pode ser bastante interessante.

c) Levantamento de dados: feitos em prontuários de pacientes ou em bancos de dados 
Silva LFF. Iniciação científica: contexto e aspectos práticos.

pré-existentes. Neste processo geralmente o aluno faz um levantamento de pacientes com uma determinada doença ou característica e colhe dados relevantes dos prontuários para montagem de um banco de dados com informações para correlação. Outra forma de levantamento de dados é a realização de entrevistas diretamente com o paciente ou com familiares destes.

d) Análises de imagem: bastante comuns na patologia, radiologia e medicina nuclear. Atualmente os computadores têm ajudado bastante a realização destas análises para identificação e contagem / aferição de diferentes parâmetros como quantidade de determinado constituinte tecidual, dimensões de um órgão, entre outros.

Como se vê as possibilidades são muitas, suficientes para atender à heterogeneidade de alunos que temos na FMUSP. Escolha as coisas com as quais você mais se identifica e acha interessante ou aquelas que têm curiosidade em aprender, este sempre é o melhor caminho!

\section{Como escolher um orientador? E o que esperar do meu orientador?}

O orientador é parte fundamental do projeto de iniciação científica porque é ele que deve ajudar o graduando nos primeiros passos dos diferentes processos descritos anteriormente. Neste processo o tempo necessário não é pequeno de forma que é importante que o orientador de fato seja uma pessoa com disponibilidade para apoio a estas atividades. Disponibilidade aqui não quer dizer exclusividade ou que seu orientador fará somente isso, mas que seja possível conversar, sentar e discutir os diferentes passos do projeto e ir resolvendo suas dúvidas e angústias.

Dica: Não escolha seu orientador pela formação básica (médico, biólogo, biomédico, etc.) ou pela posição institucional (assistente, docente, titular), isso não necessariamente garante um bom orientador, dê preferência as características dele de bom pesquisador, de disponibilidade e de interesse na relação com alunos de graduação. As dicas da questão seguinte também podem ser adotadas neste item.

Tenha sempre uma relação saudável com seu orientador, deixe-o a par de quaisquer problemas e dificuldades. Às vezes mesmo algo que parece muito complicado ou insolúvel em termos científicos, pode ser mais facilmente trabalhado com o apoio de alguém mais experiente, e lembre-se, seu orientador não é apenas alguém que pode te ajudar no projeto científico, mas também com outras questões relacionadas à sua evolução na faculdade e muitas vezes, fora dela!

\section{Como escolher um laboratório para fazer iniciação científica?}

Primeiro, lembre-se que você não precisa ter uma opinião formada sobre uma área específica para desenvolver um trabalho de iniciação científica. Como o método é mais importante que o tema em si, bons trabalhos de iniciação científica podem ser desenvolvidos em qualquer área, mas, obviamente, ter afinidade com o tema e com o trabalho desempenhado ajuda muito o desenvolvimento do projeto. Para tanto creio que três aspectos são importantes:

1. laboratórios que recebem vários alunos de iniciação científica geralmente já estão acostumados com o processo e com tudo o que está envolvido no trabalho de orientação a alunos de graduação, de forma que você possivelmente entrará num grupo que já conhece os potenciais e limitações de jovens pesquisadores como você. Mas lembre-se, isto de forma alguma desabona outros laboratórios;

2. a opinião dos veteranos sempre ajuda! Por terem vivido ou estarem vivendo a experiência da iniciação científica em diferentes laboratórios, eles poderão dar dicas valiosas sobre laboratórios onde se sentem bem acolhidos ou não, onde recebem mais atenção ou não e assim por diante. A propaganda é a alma do negócio e não existe opinião melhor que a do usuário/consumidor!;

3. Experimente! Ninguém é obrigado a saber por antecipação se gosta do ambiente ou do trabalho desenvolvido em um laboratório. Ao se interessar por algum, converse com os responsáveis e peça para acompanhar um pouco as atividades do laboratório. Geralmente 2 a 3 meses são suficientes para conhecer as pessoas, as linhas de pesquisa, as principais técnicas utilizadas e sobretudo para você perceber se você se enquadra neste grupo. Nenhum laboratório achará isso ruim e isto é uma boa oportunidade de conhecer bem a pesquisa e os métodos utilizados antes de assumir a responsabilidade de tocar um projeto.

\section{Preciso fazer iniciação científica na área de especialidade que quero fazer depois?}

Definitivamente não! Lembre-se, o objetivo da iniciação científica é conhecer e aplicar o método científico. Nesta fase da formação isto pouco ou nada tem a ver com a especialidade que você quer seguir. Fazer pesquisa é considerado bastante importante, mas não em uma área específica. Portanto, não se 
preocupe em esperar decidir uma área para fazer iniciação científica.

\section{Quais as obrigações do aluno de iniciação científica?}

O projeto de iniciação científica é uma responsabilidade grande. Ao escrever seu projeto, você se compromete na execução de um trabalho num determinado tempo e na apresentação e divulgação de seus resultados pelos diferentes meios já descritos. A maior parte dos projetos de iniciação científica são pequenos projetos dentro de grandes linhas de pesquisa dos laboratórios. Em geral estes projetos podem estar vinculados a teses de mestrado ou doutorado, ou ainda a grandes projetos temáticos financiados, de forma que o conhecimento ali produzido pode ser fundamental não apenas para incrementar a ciência como um todo, mas também para que o próprio laboratório desenvolva outras pesquisas como desdobramento do seu projeto.

Ao se comprometer com uma determinada carga horária ou com prazos, cumpra-os. Todos entendem que a iniciação científica é uma atividade adicional, funcionando como atividade optativa no atual currículo da faculdade de medicina, em meio a diversas outras atividades curriculares, portanto, seja realista ao informar ao seu orientador sobre o tempo que pretende empregar nas atividades de iniciação científica (períodos por semana e tempo ao longo da faculdade) - isto será importante para definir a magnitude do seu projeto afinal, quanto maior a disponibilidade de tempo mais complexo pode ser o projeto.

Se no ínterim surgirem problemas de tempo ou andamento, sempre converse com seu orientador de forma clara sem receio de retaliações. Ao contrário, isto demonstrará sua responsabilidade para com o projeto e o laboratório caso encontre dificuldades.

O método científico deve ser aplicado de forma rigorosa, portanto, cuidado ao realizar experimentos controlados ou a coletar dados. Estes processos devem ser feitos de forma sistemática. Sempre que você tiver dúvidas não hesite em perguntar ou discutir posteriormente com seu orientador. Por vezes, uma dúvida não solucionada pode levar a um erro experimental e a resultados incongruentes de difícil interpretação. Lembre-se em pesquisa não se pode apelar para o "jeitinho".

\section{Iniciação com bolsa ou sem bolsa?}

Diversas instituições oferecem bolsas a alunos de graduação para realização de projetos de iniciação científica. Em nosso meio as principais são a FAPESP mantida pelo governo estadual, o CNPq mantido pelo governo federal e a própria Universidade de São Paulo. As bolsas têm valores variáveis de acordo com a agência de fomento e duração de um ano podendo ser prorrogada por mais tempo em caso de ampliação do projeto ou de realização de novo projeto.

Lembre-se que o graduando não pode receber mais de uma bolsa ao mesmo tempo, nem ter outra fonte de rendimento durante o período de recebimento da bolsa.

A bolsa não é condição sine qua non para realização de iniciação científica, isto é, um trabalho de iniciação científica realizado sem bolsa é considerado uma iniciação científica tanto quanto aquele realizado com bolsa. $\mathrm{O}$ aprendizado sobre o método científico e o mais importante. Mas, se ainda assim, você quiser um indicador mais objetivo de relevância de um trabalho (incluindo o de iniciação científica) não é a existência de bolsa associada, mas sim o resultado obtido em termos de divulgação da ciência, isto é, uma iniciação científica que rendeu artigos e apresentações em congresso pode ser considerada, por estes critérios, mais bem sucedida do que uma que não resultou nestes subprodutos independente de ter havido ou não bolsa em qualquer delas.

Independente da bolsa, a responsabilidade para com o laboratório e seu orientado é a mesma, mas lembre-se, ao receber uma bolsa, você também terá que prestar contas à agencia de fomento financiadora. Isto geralmente é feito através de dois relatórios, um parcial (no meio do período) e um final. Algumas agências podem exigir ainda participação em algum evento científico.

\section{Quanto tempo preciso empregar na iniciação científica?}

A iniciação científica é uma atividade bastante valorizada na FMUSP e atualmente pode ser computada como atividade optativa dentro do currículo da Faculdade. O tempo a ser empregado na iniciação científica deve respeitar aos seus anseios bem como levar em conta outras atividades extra-curriculares que você planeja ou já desenvolve. Alguns alunos encaram a iniciação científica como sua única atividade extra-curricular, outros procuram dividir seu tempo entre diversas atividades incluindo a iniciação. Nenhuma das abordagens é incorreta, mas isto deve estar claro em sua organização e deve ser informado ao seu orientador. Com base nisso ele poderá Ihe auxiliar na montagem de um projeto que seja compatível com o seu tempo disponível para estas atividades. Considere a possibilidade de reservar pelo menos um período por semana para a realização do seu trabalho.

Este cuidado é ainda mais importante quando 
Silva LFF. Iniciação científica: contexto e aspectos práticos.

há uma bolsa de iniciação científica envolvida em que prestações de contas de atividades devem ser feitas para agências de fomento.

\section{Quais os aspectos éticos envolvidos?}

Toda a ciência é regida por uma série de preceitos éticos que evoluem com o tempo e são frutos do pensamento comum da comunidade científica num dado momento, portanto, não tente fazer hoje nada parecido com o que Edward Jenner fez do século XVIII que colheu o fluido exsudado das feridas de vacas com varíola e injetou num menino que não morreu e se tornou imune à varíola humana. Com este experimento Jenner revolucionou a imunologia e a medicina, criou a vacina e a base para evitar biIhões de mortes desde então, porém um experimento como este não seria aceito com naturalidade pela comunidade geral e científica.

Portanto, ao escrever seu projeto, ele deverá ser submetido a uma comissão de ética para avaliação de projetos de pesquisa. A FMUSP e o HC têm uma destas comissões, a CAPPesq. Pareceristas lerão o seu projeto e vão avaliar se está de acordo com as normas estabelecidas ou se devem ser feitas alterações. Em casos de seres humanos será necessário também que o paciente assine um termo específico de concordância chamado de Termo de Consentimento Livre e Esclarecido. No caso de experimentos animais, existem regras claras para evitar seu sofrimento tanto durante os experimentos quanto no momento do sacrifício. Estas regras devem ser sempre estritamente observadas.

Uma outra questão ética importante deve ser mencionada, especialmente na era dos documentos eletrônicos em que o chamado "Copy and Paste" virou moda. A cópia de parte de textos científicos, ou mesmo sua idéia central sem citar as devidas referências é créditos e considerado plágio, um dos pecados capitais em ciência. Obviamente informações de outros autores podem e devem ser citadas em sua introdução e discussão, mas sempre dando os devidos créditos. A idéia é o bem mais precioso em ciência, roubá-lo é um crime!

O mesmo raciocínio se aplica aos dados, o segundo bem maior de uma pesquisa, depois da idéia que a concebeu. Os dados devem sempre ser gerados e colhidos respeitando os preceitos do método científico. Forjar ou maquiar dados é outro dos pecados capitais da ciência. Um resultado negativo real é sempre melhor que um resultado positivo maquiado.

Estes dois últimos aspectos são particularmen- te importantes quando consideramos que o bem mais precioso de um pesquisador é a sua credibilidade. Um pesquisador sem credibilidade é como um carro de luxo sem motor: é, na prática, desprezível.

\section{O que dizer de revistas científicas, indexação e índices de impacto}

Revistas científicas definitivamente não são todas iguais. As revistas são categorizadas de acordo com diversos critérios. Simplificadamente vou apresentar dois deles:

1. Indexação - diz respeito à inclusão dos artigos de uma determinada revista numa determinada base de dados. Existem atualmente diversas bases de dados, as mais comuns no nosso meio são - Medline que inclui as mais relevantes revistas na área de saúde do mundo e o SciELO, uma base de dados específica de trabalhos publicados na América Latina. O Medline é a base de dados utilizada pelo PubMed para listar artigos, assim, ao procurar artigos no PubMed, você estará acessando apenas revistas indexadas no Medline. Este tipo de indexação busca servir como um primeiro crivo, já que as revistas, para serem indexadas no Medline, precisam respeitar alguns critérios de periodicidade, corpo editorial, entre outros.

2. Fator de impacto - a publicação de um artigo é importante, mas mais importante é que ele seja lido e sirva como referência para outros trabalhos. É com base nisso que foi criado o fator de impacto de uma revista. Ele mede o quanto, em média, os artigos publicados naquela revista são citados por outros artigos em um determinado período (geralmente 5 a 10 anos posteriores à publicação). Desta forma, revistas com alto nível de impacto são consideradas mais importantes do que aquelas com baixo índice de impacto. Apenas para situar, atualmente o fator de impacto (JCR/2011) da revista Science é de 31.201 , o da Nature é 36.280, o do New England Journal of Medicine é de 53.298. A revista nacional de maior fator de impacto é o Memórias do Instituto Oswaldo Cruz com 2.147 e a Clinics, revista científica do HC-FMUSP tem impacto de 2.958 (2 $2^{-}$colocada no país).

No momento de conclusão do seu trabalho, seu orientador saberá sugerir uma revista adequada levando em conta as características do trabalho, sua originalidade e seu potencial.

\section{É importante para a residência?}

Na Faculdade de Medicina e no Hospital das Clínicas da FMUSP a iniciação científica é conside- 
rada uma atividade muito importante pois cria bases relevantes para a compreensão das atualizações científicas que são disponibilizadas diariamente numa instituição universitária. Neste sentido é interessante que os residentes desta instituição tenham boa base científica.

Estas atividades são avaliadas no conjunto da análise curricular - constante da $3^{\mathrm{a}}$ fase do processo seletivo. Mas um aspecto deve ser ressaltado, via de regra a área em que a iniciação foi realizada não é relevante (isto é, não precisa ter feito a iniciação científica na área para a qual você está prestando residência).

\section{REFERÊNCIAS SUGERIDAS}

Bariani ICD. Estilos cognitivos de universitários e iniciação científica [Tese]. Campinas: Faculdade de Educação, Universidade Estadual de Campinas, Campinas; 1998.

Cardoso GP, et al. Iniciação científica em medicina: uma questão de interesse para todas as especialidades. Pulmão (RJ). 2004;13(1):8-12.

Conselho Nacional de Pesquisa e Desenvolvimento - CNPq. Disponível em: http://www.cnpq.br.

Fava de Moraes F, et al. A iniciação científica - muitas vantagens e poucos riscos. São Paulo Perspect. 2000;12(1):73-7.

Jacobs CD, et al. The value of medical student research: the experience at Stanford University School of Medicine. Med Educ. 1995;29:342-6.

Martinho TP. Scientific initiation in medical education. Med Teach. 2005;27(1):81-2.

Massi L, et al. Estudos sobre iniciação científica no Brasil: uma revisão. Cad Pesq. 2010;139(40):17397.

\section{CONSIDERAÇÕES FINAIS}

Ao decidir fazer iniciação científica inicialmente alinhe suas expectativas e veja os temas e técnicas que mais lhe interessam. Busque um bom laboratório e um bom orientador. Lembre-se, nem sempre se acerta de primeira, portanto experimente, conheça os laboratórios e as pessoas. Uma vez definido, escreva seu projeto e execute-o da melhor forma possível, fazendo ciência ao mesmo tempo em que descobre as maravilhas e infortúnios envolvidos. Este é um processo que certamente será enriquecedor para a sua formação técnica e pessoal independente de você querer ou não fazer pesquisa no futuro!

Brasil. Ministério da Educação. Instituto Nacional de Pesquisas e Estudos Educacionais Anísio Teixeira (INEP). Informativo do Inpe Online. 2005;3(98) [citado fev. 2012]. Disponível em: http://www/inep.gov.br/ informativo/informativo98.htm.

Montes GS. Da implantação de uma disciplina de iniciação científica ao currículo nuclear na graduação em medicina na USP. Rev Bras Cardiol. 2000;2(2):70-7.

Oliveira NA, et al. Iniciação científica na graduação: o que diz o estudante de medicina? Rev Bras Educ Med. 2008;12(3):309-14.

Pego-Fernandes PM, et al. Medical education beyond graduation: scientific initiation. Sao Paulo Med J. 2010;128(3):117-8.

Tenório MP, et al. Iniciação científica no Brasil e nos cursos de medicina. Rev Assoc Med Bras. 2010;56(4) 375-93.

Velho L, Velho P. A Iniciação Científica (IC) nos Estados Unidos: mecanismos instrumentos e recursos alocados. Educ Bras. (Brasília). 1998;20(41):11-47. 